\title{
Cultura de paz desde las aulas. Un encuentro entre Potter y Freire ${ }^{1}$
}

\author{
Culture of Peace from the Classroom. A Meeting \\ Between Potter and Freire
}

\section{Cultura de paz da sala de aula. Um encontro entre Potter e Freire}

\author{
Alida Chaparro Barrera ${ }^{2}$ \\ Universidad Militar Nueva Granada, Bogotá, Colombia \\ alidabarrera013@gmail.com
}

Recibido: 19/11/2016 Aprobado: 03-05-2018

[...] Vivimos en un tiempo tan brutal, tan despiadado, que tenemos que preguntarnos continuamente si no estamos soñando. Incluso cuando reconocemos el dolor y la desesperación de tantos que viven en un estado de desequilibrios nacionales e internacionales, aunque nos espantamos ante el grado de explotación capitalista y la degradación ambiental de nuestro mundo contemporáneo, permanecemos prisioneros de la ilusión de que vivimos en el mejor de los mundos posibles $[\ldots]$

(McLaren, 2006)

1 Artículo elaborado como complemento de los requisitos para la Candidatura a Doctora en Bioética, Universidad Militar Nueva Granada, Bogotá, Colombia.

2 Magister en Educación. 
Cultura de paz desde las aulas.

Un encuentro entre Potter y Freire

\title{
Resumen
}

En este artículo de revisión se reflexiona sobre la bioética de Van Rensselaer Potter y la pedagogía de la liberación de Paulo Freire, y algunas semejanzas y diferencias que interactúan como fundamentos para promover una cultura de paz. Los objetivos son identificar la postura de los autores, establecer interacciones entre sus postulados, y definir estrategias que fundamenten una cultura de paz y compromiso de la educación. Se muestra el recorrido bibliográfico que respalda el proyecto "Entre bioética y pedagogía de la liberación, propuesta de educación para la paz en Colombia”. Se usó una metodología cualitativa, orientada a la revisión bibliográfica, con análisis comparativo soportado en el método hermenéutico que hace posible la comprensión de términos y significados; para el registro de la información se utilizó la ficha de contenido. Se concluye que para empezar a consolidar una cultura de paz desde las aulas se requieren sólidas bases teóricas, reformulación de planes de estudio, currículos y políticas públicas, que posibiliten proyectos sociales y pedagógicos pertinentes e inclusivos, que transformen ámbitos de violencia cotidianos.

Palabras claves: bioética; bioética y pedagogía liberadora; cultura de paz; educación para la paz; supervivencia.

\begin{abstract}
This review article reflects on Van Rensselaer Potter's bioethics and Paulo Freire's liberation pedagogy, and some similarities and differences that interact as foundations to promote a culture of peace. The objectives are to identify the position of both authors, establishing interactions between their postulates, and defining strategies that support a culture of peace and commitment from education. The bibliographic path that supports the project "Between bioethics and pedagogy of liberation, proposal of education for peace in Colombia" is presented. A qualitative methodology was used, towards the orientation of the bibliographic revision, with comparative analysis supported in the hermeneutic method that makes possible the understanding of terms and meanings; for the record of the information the content-card file was used. It is concluded that to begin to consolidate a culture of peace from the classroom, solid theoretical bases, reformulation of curricula, and curricula and public policies are required, to enable relevant and inclusive social and pedagogical projects that transform the daily violence spheres.
\end{abstract}

Keywords: Bioethics; liberation pedagogy; culture of peace; education for peace; survival.

\section{Resumo}

Este artigo apresenta reflexões sobre a bioética de Van Ressenlaer Potter e a pedagogia libertadora de Paulo Freire, salientando algumas semelhanças e diferenças que interagem como fundamentos para promover cultura de paz. Nessa ordem, o artigo identifica posturas dos autores, estabelece interações entre seus postulados, define as estratégias que subsidiem cultura de paz e compromisso da educação. Também, destaca o percurso bibliográfico que respalda o projeto "Entre bioética e pedagogia da libertação, proposta de educação para a paz na Colombia”. A metodologia é qualitativa, orientada à revisão bibliográfica, com análise comparativa, a partir de um método hermenêutico, que permite a compreensão de termos e significados. Utilizou-se uma ficha de conteúdo como instrumento para registrar a informação. Como conclusão identifica-se que, para consolidar uma cultura de paz dentro das salas de aula, é necessário contar com alicerces teóricos sólidos, reformulação de planos de estudo, currículos e políticas públicas que possibilitem o andamento de projetos sociais e pedagógicos adequados, inclusivos, visando transformar âmbitos de violência cotidianos.

Palavras-chave: bioética, bioética e pedagogia libertadora, cultura de paz, educação para a paz, supervivência.

¿Cómo citar este artículo? / How to quote this article?

Chaparro-Barrera, A. Cultura de paz desde las aulas. Un encuentro entre Potter y Freire. El caso de la Sociedad Rural Argentina.

Sociedad y Economía, (35), 178-197. https://doi.org/10.25100/sye.voi35.7293 


\section{Introducción}

Este artículo presenta aspectos del pensamiento de Paulo Freire que se refiere a la pedagogía liberadora desde la concienciación y la praxis, y aborda la postura de Van Ressenlaer Potter desde la mirada de la justicia, igualdad y supervivencia, como apuesta para pensar en educación para la paz.

Para alcanzar una sólida comprensión de los textos de los autores definidos, fue necesario acudir en forma exhaustiva a las grandes obras que conforman su legado, lo cual asegura legitimidad en los argumentos que, en consideración de muchos pedagogos y filósofos, especialmente, son propios para esta época, además de fundamentales, si se pretende transformar la convivencia y alcanzar una cultura de paz, que hoy más que nunca necesita Colombia. Así mismo, fue necesario el acercamiento teórico a otros autores, como sólidos referentes sobre estudios sobre paz, educación y cultura de paz, con el fin de respaldar reflexiones esenciales para este trabajo, y se constituyan en soporte para emitir algunas conclusiones.

El objetivo de este artículo se dirige a establecer interacciones que se encuentran entre bioética y pedagogía liberadora desarrollando un ejercicio hermenéutico serio y responsable. Para alcanzar lo expuesto se inicia con la presentación de Potter y Freire, se aborda la visión antropológica de los autores, que definen una perspectiva de concienciación, fundamento para la pedagogía de Freire y la bioética, la praxis como respuesta a la reflexión desde la toma de conciencia, se hizo acercamiento a algunos enfoques de paz, de educacion para la paz y cultura de paz, como sustentos teóricos, para finalmente elaborar las conclusiones propias para un trabajo de esta naturaleza.

\section{La metodología}

Este trabajo se adelantó mediante el paradigma cualitativo con enfoque en la investigación documental o bibliográfica, apoyado en el método hermenéutico y respaldado por el analítico-sintético; recordando que, según Hurtado y Toro (2007), "análisis y síntesis son procesos estrechamente unidos, inherentes al acto humano de pensar" (p. 66), que, para el caso, son complementarios. Gracias al proceso de síntesis se elaboraron los resultados como producto final. El paradigma cualitativo posee un fundamento indudablemente humanista, conduce a entender y comprender realidades y resalta una concepción evolutiva.

La hermenéutica refiere la capacidad y talento para interpretar texto, comprenderlo, colocarlo en contexto y entender al autor, así como su contenido e intención; de acuerdo con Rojas (2011) "la hermenéutica es un recurso científico orientado a la comprensión de actos de habla, de la acción social cifrado en la dimensión genérica de textos" (2011, p. 188).

Se dio paso al proceso de comprensión y análisis de los discursos de estos autores con el fin de identificar elementos esenciales tanto de la bioética de Potter como de la pedagogía de la liberación de Freire, y se dedujeron algunas distancias y aproximaciones. La acción hermenéutica permitió encontrar elementos que se conjugan en contextos sociales, económicos y políticos con realidades históricas distantes. A pesar de ser teóricos de distintas disciplinas, concuerdan en algunas perspectivas con respecto al ser humano, la supervivencia, concienciación, educación y cultura; aspectos que se instauran como ejes en torno a los cuales gira la propuesta y se constituyen en fundamentos para promover cultura de paz desde las aulas, teniendo como precedente que a la educación le corresponde empoderarse de su función de formadora para construir una nueva sociedad.

La metodología fue recomendada por expertos en el tema, que la consideraron apropiada en razón a que exige una búsqueda minuciosa de bibliografía, lectura responsable de los contenidos, análisis preciso de los temas para lograr entender y comprender su esencia, considerando según Echeverría, (1997) que "la tarea metodológica del intérprete (...) consiste en encontrar 
Cultura de paz desde las aulas.

maneras lógicas de interacción entre su propio horizonte y aquel del cual el texto es portador" (1997, p. 220).

Es bien sabido que en un ejercicio de esta naturaleza se presentan limitaciones por lo general asociadas con el tiempo, lo cual constituye un condicionante en razón a la cantidad de contenido bibliográfico tanto de Potter como de Freire, así como bases relacionadas con el tema de la paz que son copiosas y densas, por lo que fue necesario optimizar la selección, el registro y la consolidación de datos en forma ordenada y precisa para alcanzar lo propuesto.

\section{Resultados}

Las acciones preliminares para la sistematización del contenido bibliográfico permitieron que la autora de este trabajo se introdujera en el pensamiento de Van Ressenlaer Potter, lo cual hizo posible reconocer la importancia de los aportes del científico que luchó por encontrar las más altas posibilidades contra el cáncer sobre lo que investigó incansablemente gran parte de su vida; trabajo que lo llevó a concluir que este tipo de estudios no solo eran insuficientes para proteger y mantener la vida y un mundo mejor para todos, sino que era indispensable proponer una nueva disciplina que se preocupara por el cuidado integral de todos los seres vivos. No en vano escribió que "la supervivencia de la naturaleza, incluido el hombre corre peligro" Potter (1970, p. 1), razón de más para pensar que a la humanidad le corresponde mayor conciencia responsable para evitar tantos daños en la integridad de la vida y destrucción de la naturaleza.

No menos importante ha sido el encuentro con la esencia de Paulo Freire, pedagogo brasileño, de inagotable horizonte liberador, válido para la sociedad mundializada de hoy, donde cada una de las naciones requiere de visión emancipadora e identidad propia para involucrarse en la aldea global, sin perder su autonomía y libertad y participando de todos los movimientos que esta época trae consigo. La liberación a la que tanto se refiere Freire exige el reconocimiento de la realidad individual y colectiva como fondo para comprender las necesidades de la nueva humanidad, de donde debe surgir la resignificación de la misma con actitud crítica y reflexiva, lo que el autor ha designado concienciación, base fundamental para construir una sociedad que piense en una liberación pacífica, razonada, real, que crea en la educación como pilar imprescindible para consolidar la paz, construirla desde la reflexión y la praxis, proceso permanente para mejorar y proteger la vida con dignidad; al respecto Freire (1969) manifiesta: "La educación verdadera es praxis, reflexión, acción del hombre sobre el mundo para transformarlo" (p. 7).

\subsection{Bioética de Potter y pedagogía de la liberación de Freire}

Potter y Freire son actores que corresponden casi a la misma década en cuanto a su nacimiento, se destacaron por sus ideas políticas, sociales, económicas y científicas de mitad del siglo $\mathrm{XX}$; aunque pertenecían a entornos geográficos y socioeconómicos diferentes, desarrollaron sus obras en momentos críticos de la historia, cuando la situación en cada una de sus regiones atravesaba tiempos de especial relatividad axiológica, pérdida de derechos y valores, empobrecimiento, miseria, utilización del ser humano como medio para obtener resultados científicos en menoscabo de su dignidad y respeto. Aún hoy se vive la misma situación, a mi juicio tal vez peor.

Potter, eminente médico y bioquímico, nació en 1911 en una granja en Dakota del Sur, Estados Unidos. Dejó una imborrable huella en la humanidad y forjó un camino en busca de la protección, respeto y cuidado por la integridad de la vida de las personas y todos los seres vivos. Trabajó por disminuir y evitar el dolor en los seres humanos, producido algunas veces por padecimientos naturales, y otras cruelmente provocado por otras personas.

Se dedicó a la investigación oncológica en la Universidad de Wisconsin; su reflexión y experiencia lo llevaron a entender que era inminente 
buscar una unidad de conocimiento que permitiera utilizar la investigación sin ocasionar daño a la vida e integridad de la persona, por lo que pensó en la bioética como posibilidad de sabiduría para utilizar el saber científico en forma más justa y adecuada para bien y en favor de la existencia humana y natural. Llegó a la bioética realizando estudios en sobrevivencia que llevaban una trayectoria desde 1962; tal parece que el término bioética le surgió hacia finales de la década de 1960: "He escogido la raíz bio como representante del conocimiento biológico y las ciencias de los sistemas vivientes y ethics para referirme al sistema de valores humanos" Potter (1970, p. 1). Desde mi punto de vista, una combinación excepcional que hoy más que nunca se requiere en este mundo convulsionado que transita hacia un rumbo impredecible de destrucción.

Desde siempre fue un defensor de la vida, pero de una vida con calidad, digna, máxima, como se dice popularmente, intensa y plena; por eso pensó en la supervivencia, y no en vano se refirió, entre otras, a la supervivencia aceptable, supervivencia miserable y simplemente la supervivencia, que otorgue integridad, derechos, justicia y libertad, y sobre todo que gire en torno a la responsabilidad y compromiso que debe tener el hombre frente a la conservación de la naturaleza como fuente de vida. Razones de más para que expresara:

\footnotetext{
Existe un serio peligro que corre la supervivencia de la naturaleza, incluido el hombre, por descuido de él mismo y concretamente de los especialistas que están agotando los recursos naturales, olvidándose de una verdad ancestral: necesitamos de la naturaleza para sobrevivir, si esta se acaba, nos acabamos todos (Potter, 1970, p. 127).
}

La propuesta del autor precisa acudir a la bioética, no únicamente desde y para las ciencias médicas, pues eso sería excluyente, a sabiendas de la gran cantidad de problemas que enfrenta la humanidad; se refiere a la bioética que pueda acercarse a las diversas relaciones que tiene el hombre con el mundo, que fundamente el compromiso y la responsabilidad humana como bases para alcanzar una existencia digna, saludable y feliz como posibilidad para mejorar la vida en todos sus ámbitos y una forma de construir paz en beneficio de todos.

Parafraseando a Ángela María Wilches (2011), para Potter la bioética debe ser una disciplina que fundamentalmente surja de lo que el mismo autor definió como "crisis de hoy", que es generalizada y global, tanto que afecta al individuo, la sociedad y al medio ambiente; razón de fuerza para definir que será a través de la educación que el ser humano llegue a la comprensión indiscutible de las realidades de la vida, y vea la necesidad de asumir la responsabilidad que le corresponde como protagonista de los cambios que necesitan todos los seres vivos para su bienestar, conservación y progreso.

En ese orden de ideas, la bioética es un puente que une saberes y dimensiones en beneficio de la humanidad; como puente, fue el inicio del pensamiento integrador, como global fue moralidad manifiesta en todas las acciones del ser humano y ambiental, la bioética hace posible la interacción entre salud humana y salud ambiental que conforman una realidad de vida.

Paulo Freire, abogado, pedagogo y educador brasileño, es pernambucano nacido en el seno de una familia pobre, sencilla, que sobrellevó el infortunio y las carencias. De brillante y amplia trayectoria, en cuanto a pedagogía como oficio de educar y formar generaciones más humanas, libres, conscientes, pone al servicio de la humanidad uno de los paradigmas más solventes de la pedagogía contemporánea, que enseña a educar en el amor, el ejemplo, en favor de la libertad, la igualdad y el reconocimiento a los desfavorecidos y desde la praxis. En consecuencia, su propuesta no se funda en cómo hacer para adquirir más conocimientos, sino en cómo hacer para que todas las personas aprendan a ser más conscientes, responsables y capaces de cambiar el mundo.

Gestor de nuevas generaciones, hace énfasis en la formación equitativa para todos, especialmente para los que sufren, los adultos y los pobres. La educación que propone está definitivamente permeada por la discriminación 
y deshumanización, razón por la que en sus postulados lucha por la legitimidad, fraternidad y compasión. Su teoría sobre el conocimiento surge de la realidad sentida en el propio contexto (nordeste brasilero). Los fundamentos de su propuesta están influenciados entre otros, por el personalismo de Emanuel Mouriner y Jacques Maritain en cuanto a "las concepciones de amor, comunicación, conciencia", por las ideas filosóficas de la existencia, representadas sobre todo por Karl Jaspers y Gabriel Marcel, en lo que se refiere a "temporalidad e historicidad", por la visión antropológica de Max Scheler porque el eje en torno al cual gira el pensamiento Freiriano es el hombre como totalidad, la influencia del marxismo en cuanto sostiene una propuesta de cambio, una convocatoria al compromiso y a la transformación de la realidad a partir de la revolución y responsabilidad de las ideas, lo cual se manifiesta según Freire, en despertar una conciencia crítica que produce la reflexión-acción, así mismo se percibe alguna coincidencia con el psicoanálisis de Erick Fromm por cuanto consideran que la conducta y el carácter de los individuos son influenciados por el medio social y económico en que se desarrollan. Estos fundamentos enmarcan de alguna forma la estructura del pensamiento de Freire.

La bioética de Potter y la pedagogía de Freire tal parece iniciaron un camino buscando entendimiento y sabiduría y encontraron una compleja situación social que amerita rescatar al ser humano y a la sociedad como eje central para la vida y fundamento para el cambio.

\subsection{Dimensión antropológica de Potter y Freire}

\footnotetext{
La situación antropológica del hombre surge como consecuencia del sentido de frustración, desilusión y vulnerabilidad de la condición humana (...) los fracasos de la vida personal y colectiva llevan sin duda a cuestionarse, si la vida tiene sentido o si hay motivo para vivir (García, 2014, p. 23).
}

Toda práctica humana lleva implícita una concepción del ser humano y del mundo, incluyendo la educación, proceso conformado entre otros aspectos por acciones humanas. Por tanto, "no existe educación sin sociedad humana y no existe hombre fuera de ella" Freire (1969, p. 25). A ese respecto, Perdomo (2009) considera que "la concepción antropológica de Freire puede ser contextualizada atendiendo la diversidad de dimensiones del pensamiento humano que sirven como espacio para la reflexión, creación y recreación de su discurso" (p. 8).

Parafraseando a José Luis García (2014), Freire supone que desde la dimensión política, el ser humano es apenas un medio electoral que sirve para mantener al gobierno de turno; desde la dimensión económica es una máquina para la producción, un instrumento útil para acrecentar el capital, un objeto de consumo; desde la dimensión ideológica, existen algunas corrientes de pensamiento fatalista, determinista, absolutista y mecanicista, cuyos planteamientos reducen y relativizan la realidad del fenómeno humano y someten al hombre mediante condicionamientos biológicos, psicológicos y sociológicos; desde la dimensión social, no es más que un hombre degradado por la constante violación de los derechos humanos, la pobreza, miseria, muerte, desempleo, hambre, , desplazamientos, amenazas, intolerancia; y desde lo científico, no es más que un objeto para experimentar, un medio para la ciencia, en menoscabo de su dignidad y olvidando su condición de humanidad. Desde lo filosófico dice Freire (2002) "el hombre es un ser que ontológicamente es "para sí", se "transforma" en "ser para otro", no está solo, está en el mundo, es un ser de relaciones con el mundo, (...) que se proyecta hacia otros y trasciende" (p. 9).

En efecto, Freire destaca que el crecimiento del hombre se da en el encuentro con los demás, en las relaciones que hacen posible el entendimiento como extensión humana de coexistencia, donde su hacer, sus experiencias, actitudes y sentimientos son el presupuesto para pensar en otras realidades. Vale tener en cuenta el texto de Pineda (2008):

La concepción de ser de Freire entraña una visión comunitaria, amplia, en la cual el 
respeto, la diversidad cultural, la temporalidad, la reflexión, (...) se convierten en parte de la existencia (...). Es una visión dialéctica en la que concibe la existencia como algo que se hace constantemente, producto de la praxis humana, por lo tanto, el ser es una condición de ser humano en tanto sea colectiva y dialéctica (p. 5).

Para Freire (1986a) el ser humano como forma corporal -cuerpo- consciente se integra en el quehacer cotidiano en el mundo desde lo intelectual y lo vital como un todo concreto, por lo que refiere:

\footnotetext{
El cuerpo humano viejo o joven, gordo o flaco, no importa de qué color, es el cuerpo que lucha, que ama, que odia; el cuerpo que sufre, muere, vive. Son acciones del ser humano que están absolutamente ligadas con las experiencias en la vida cotidiana con toda su energía y creatividad, sumando a esta cotidianidad la relación de los sentimientos como expresión corporal, sentimientos de alegría, tristeza, cariño, afecto, todo lo que tiene que ver con el ser humano (p. 32).
}

En la propuesta de Freire es indudable la unión entre hombre y mundo a través de permanentes interacciones que se sustentan en la praxis como quehacer fundamental para la transformación.

Para la bioética, hombre refiere toda individualidad y posee mayor valía que las cosas, ser alguien y algo como sustancia que ostenta dignidad y libertad, por tanto, las personas no son medios, sino fines en sí mismas, razón de más para definir que en el marco referencial de la bioética se le otorga valor al ser humano y no precio; principio de justicia por el que todas las personas merecen la misma y absoluta consideración y respeto.

La bioética se apoya en una antropología personalista, cuyo principio es la condición real de ser humano, es una visión integral del individuo que posee dimensiones también individuales que lo hacen persona, capaz de reflexionar acerca de sí mismo, acerca de su ser humano, inquietud permanente que le obliga a hacerse preguntas en torno al ser propio. La persona se constituye en el centro y el criterio de las consideraciones de la bioética.

Tanto para Potter como para Freire el problema del hombre y la deshumanización de la sociedad requiere profundas reflexiones para alcanzar también profundas y necesarias transformaciones, justas, que conduzcan a mejorar el ser y estar en la vida; los autores coinciden cuando consideran que el mismo ser desde su individualidad no solo busca conocerse a sí mismo, sino que se construye en una relación dialéctica con el otro, donde se da el reconocimiento, que conduce al crecimiento y cambio como muestra de autonomía; reconocen el diálogo como fundamento ineludible para el entendimiento y la comprensión.

\subsection{Bioética y concienciación}

Según Freire el primer paso para que el individuo comience procesos de transformación es asumiendo una postura crítica frente a la realidad individual en cada contexto, es reflexionar responsablemente desde sus propias circunstancias, es pensar como sujeto dueño de su propio ser. "La concientización, como proceso permite la crítica de las relaciones conciencia-mundo, es la condición para asumir el comportamiento humano frente al contexto histórico-social" (Stheck, Redín y Zitkoski, 2015, p.105).

Cuando Freire incorpora en su discurso la concienciación, establece pautas que orientan el proceso de interpretación como la intención de observar la realidad, la cual se vuelve objeto de conocimiento y alcanza un nivel superior denominado criticidad, sigue el análisis profundo y amplio que es la trascendentalidad. Es un proceso que no se queda en la interpretación de datos, sino que refiere una comprensión concreta y propia del entorno que evidencia y proyecta cambios en la sociedad.

Dentro de la perspectiva de bioética propuesta por Potter, se encuentra el proceso de concienciación, que más que una toma de conciencia frente al cuidado de la vida y de los seres 
vivos, es un accionar permanente en favor de la especie humana. Potter reconoce la necesidad de proteger la integridad de la vida mediante una actitud de respeto, justicia y libertad consciente y responsable frente a cada acto que se ejecuta en la naturaleza. La bioética, como la ética de vida para el siglo XXI, hace énfasis en concientizar a las personas y a la sociedad de su responsabilidad en la defensa de la dignidad humana en temas relacionados con procesos biológicos, científicos, sociológicos y filosóficos.

\subsection{Supervivencia humana}

La principal preocupación de Potter es conservar la vida del ser humano y todas las especies vivas por encima de cualquier intención de la ciencia, siendo este uno de los motivos por los que escribió el artículo "Bioethics: the science of suvirval" (Bioética: la ciencia de la supervivencia), porque "la supervivencia debe ser más que una sola ciencia, por consiguiente propongo el término bioética para poder enfatizar los dos más importantes componentes para lograr la nueva sabiduría que tan desesperadamente necesitamos, conocimiento biológico y valores humanos" Potter (1971, p. 2). Está convencido que la supervivencia es superior a los adelantos que ponen en riesgo de extinción a la especie humana, para ello será necesario "comenzar con una nueva clase de ética -la bioética-, que podría denominarse "ética interdisciplinaria" que incluye las ciencias y las humanidades De la Cuesta (2005, p. 146).

En Global Bioethics Potter (1988) confirma que "la bioética es un sistema de moralidad basado en conocimientos biológicos y valores humanos con la especie humana que acepta la responsabilidad por su propia supervivencia y la preservación del entorno natural" (p. 154), y sugiere algunas categorías de sobrevivencia: básica, miserable, ideal, irresponsable y aceptable. $\mathrm{Al}$ respecto define Benavides (2012)

La sobrevivencia básica implica sólo disponer de alimentos y albergue, la miserable involucra la vida al borde de la inanición y de la muerte por enfermedades principalmente infecciosas. La sobrevivencia ideal, puede darse en distintos niveles económicos, en distintas culturas y ocurre cuando un porcentaje importante de la sociedad posee la seguridad económica, la información y el comportamiento ético para promover la salud, la sobrevivencia irresponsable opuesta a la ideal, representa el proceder irresponsable y la no preocupación por el presente ni por el futuro, el proceder egoísta basado en los intereses de unos cuantos sin importarles la salud de los ecosistemas, (...). La sobrevivencia aceptable es la basada en una actitud responsable hacia el individuo, la especie y la biósfera (p. 20).

Frente a la postura de Potter, Quicutis (2013) reseña que el autor no es ajeno a la visión de Freire en cuanto "la perspectiva del oprimido que tiene ante sí la urgente tarea de desarrollar conocimiento y valores para alcanzar la libertad que le puede devolver la condición de humanidad" (p. 161) es la obligación de salir de la opresión y alcanzar su libertad, como apuesta a la supervivencia, asumir el derecho a pensar y transformar su condición, con el más grande deseo de acabar con el estado de desigualdad e inequidad y rescatar la vida.

Freire y Potter coinciden al considerar que las acciones que los individuos realizan por alcanzar la libertad y salir de la dominación son una muestra de la defensa por tener una vida digna y dejar la supervivencia miserable, por asumir y recobrar la posición y valor de ser humano, salir del estado de marginalización. La humanidad reclama igualdad y justicia esenciales para la supervivencia digna.

Son puntos solidos de encuentro entre los autores, los dos han trabajado por y para la vida, por y para la persona, están de acuerdo que es fundamental el conocer y la comprender plenamente todas las circunstancias y condiciones del entorno, reconocer el alcance y los límites de la ciencia, mantener viva la esperanza para trabajar por las necesidades propias y las de los demás. Hoy el ser humano debe empoderarse de su propia supervivencia y del cuidado de la naturaleza a partir de procesos de concientización 
de realidades y lenguajes de liberación y superación.

\section{Visión de paz}

Al hablar de paz es inevitable hablar de guerra porque históricamente han estado ligadas desde que el hombre comienza su historia en el planeta; las transformaciones económicas, políticas, sociales y religiosas se han dado mediante conflictos y guerras, en consecuencia, son inherentes a la naturaleza humana. Por lo tanto, pensar en el origen de la paz y la guerra es muy complejo. Parafraseando parte del escrito que realizó en 1999 el notable antropólogo Harris Marvin, históricamente la guerra ha sido habitual, tanto que a partir del mismo momento en que surgió la agricultura las guerras eran imparables, por expansión de esta labor, por posesión de tierras libres, por patriarcado, liderazgo, ideologías religiosas, por ambición, castas y religiones, así mismo, por la fuerza y poderío de los clanes y el ansia de poder entre los hombres. Para Clastres (2004) "la guerra no era más que una réplica de la caza, pues era una actividad que hacía posible la consecución de alimento, control de la población, obtención de tierras y recursos" (p. 20).

Entonces la guerra, los conflictos y la violencia se han dado a través del tiempo, son hechos reales, con diferentes connotaciones que hacen parte de la evolución de la humanidad y de la historia; en esa misma medida, históricamente se han dado acciones y acuerdos de paz. En ese orden de ideas también, surgen diversos conceptos de paz, que no se abordan en toda su amplitud en este estudio, sino que se tomarán algunos significados que permitan entender la paz como resultado de transformaciones alcanzadas a través del diálogo, la confrontación y el consenso. Para Ocampo (2010) la paz es "una fuerza ético-política, dinámica, transformadora y constructiva, que requiere constante seguimiento, transformación y es indispensable para el desarrollo humano y cultural" (p. 5).
En la Tabla 1 se leen concepciones de paz que también refieren la violencia que se vive en las sociedades, sin olvidar que al hablar de paz se relaciona la violencia y la guerra. Los autores coinciden en cuanto suponen que la paz es un proceso esencial para el desarrollo de la vida, que su epicentro indiscutiblemente está en la familia, que debe trabajarse, percibirse y vivirse en la escuela, y trascender en la sociedad como forma de vida.

Vale tener presente que el concepto de paz obedece a circunstancias propias de cada épo$\mathrm{ca}$, porque determinan los desafíos que deben enfrentar las sociedades en cada momento de su evolución histórica, inciden en las fuerzas dominantes políticas, religiosas, económicas y sociales, estrechamente relacionadas con la recuperación de la dignidad, y el restablecimiento de los derechos humanos, lo cual requiere de procesos de transformación desde lo personal, social y estructural, que coadyuven a cimentar una nueva sociedad tolerante y en paz. No en vano escribe Kung (1977)

El punto de partida para trabajar juntos por la paz y colaborar en la construcción de una sociedad intercultural, interreligiosa, interétnica e interracial, sin discriminación de ningún tipo, sobre las bases de la tolerancia, el respeto a las diferencias ideológicas, culturales, religiosas y la acogida solidaria a los inmigrantes (p. 9).

Nada más preciso que esta visión de paz porque se relaciona con el pensamiento de Potter y Freire quienes consideran la necesidad de rescatar una vida digna, armónica fundamentada en la responsabilidad, la equidad, la justicia y ante todo con todas las necesidades básicas satisfechas como complemento de dignidad humana. La paz es conciencia, acción, valor, convivencia, es cultura, para Aguilar y Castañón (2013)

La paz proviene del latín pax, pacis, cuyo significado es tranquilidad, perdón, permiso. Para muchas personas la paz es el fruto de la sana convivencia entre los seres humanos, y para hacerla posible es necesario un orden social justo, en el que todos los ciu- 
Tabla 1. Algunas formas de abordar el concepto de paz

\begin{tabular}{|c|c|c|}
\hline Tipos de paz & Formas & Violencias \\
\hline Paz negativa & Ausencia de violencia directa & $\begin{array}{l}\text { La violencia directa, física y/o verbal, es visible en } \\
\text { forma de conductas, responde a actos de violencia y } \\
\text { se concreta en comportamientos. Es la que realiza un } \\
\text { emisor o actor intencionado (en concreto, una persona), } \\
\text { y quien la sufre es un ser vivo dañado o herido física o } \\
\text { mentalmente. }\end{array}$ \\
\hline Paz positiva & $\begin{array}{l}\text { Ausencia de violencia estructuralmente } \\
\text { indirecta propia de las estructuras sociales } \\
\text { que soportan algún tipo de desigualdad } \\
\text { social, económica política y militar }\end{array}$ & $\begin{array}{l}\text { La violencia estructural de la que hacen parte un } \\
\text { conjunto de estructuras, físicas y organizativas, que } \\
\text { impiden la satisfacción de las necesidades. Esta } \\
\text { es la peor de las tres violencias (cultural, directa y } \\
\text { estructural), es el origen de muchas desigualdades, es } \\
\text { agresiva, difícil de distinguir, y es muy complicado } \\
\text { luchar contra ella. Es una violencia indirecta, porque } \\
\text { son derivadas indirectas de la política económica } \\
\text { capitalista y del injusto reparto de la riqueza. }\end{array}$ \\
\hline Paz neutra & Ausencia de violencia cultural /simbólica. & $\begin{array}{l}\text { Eliminadora de las violencias culturales y simbólicas. La } \\
\text { tarea de la paz neutra es la de neutralizar los elementos } \\
\text { violentos (culturales y simbólicos) que habitan en los } \\
\text { patrones que posee cada sociedad para organizar sus } \\
\text { relaciones entre los individuos, la familia, grupos y el } \\
\text { conjunto de la sociedad. }\end{array}$ \\
\hline
\end{tabular}

Fuente: elaboración propia, resultado del análisis de documentos de Jiménez (2011), Jiménez y López (2007) y Galtung (1996).

dadanos tengan las mismas oportunidades para desarrollarse y sus derechos fundamentales sean respetados (p. 72).

En ese sentido, la paz que hoy necesita Colombia no se refiere solo a acciones de perdón y olvido, sino que demanda un andamiaje integral que vincule fenómenos de violencia, pobreza, carencias, desigualdades estructurales, deterioro del medio ambiente y relaciones sociales; en consecuencia, para este país es un proceso de largo alcance que converge en la educación como proceso de formación y transformación de las personas. Porque "La paz se crea y se construye con la superación de realidades perversas. La paz se crea y se construye con la edificación incesante de la justicia social" (Freire, 1986b, p. 46).

Indudablemente, la paz se va construyendo poco a poco, promoviéndola en forma individual e interior de cada persona, que se refleje en las relaciones cotidianas en todas las instancias y colectivos sociales, sin importar que todos actúen de distintas formas, momentos y diferentes circunstancias.

En ese orden de ideas la construcción de paz debe ser un proceso dinámico, humano, social, que demanda una seria y responsable toma de conciencia frente a un sinnúmero de experiencias y realidades vividas alrededor de los conflictos y la guerra, exige respeto por la libertad y reconocimiento de los derechos humanos, cultura ecológica, la construcción de paz es una ruta multifacética que "involucra diferentes actores, visiones, escenarios, poderes, estructuras de dominio y condicionantes externos" (Sarti, 2007, (citado por Aguilar M, y Castañón, N. 2013, p.85). Dicho proceso requiere la urgente necesidad de dar un giro a la convivencia actual para conseguir cambios de actitudes, disminuir las costumbres violentas, promover formas de vida 
sana, aprender a decidir en beneficio común, cambiar comportamientos y compartir, mejorando el bienestar y la calidad de vida. A propósito, Galtung (1996) dice que "la paz no es lo contrario de la guerra sino la ausencia de violencia estructural, (...) condición para que los conflictos puedan ser transformados creativamente y de forma no violenta (...) reconociendo a los oponentes y utilizando el método del diálogo" (p. 281).

Reconocer que construir paz es construir un mundo donde prevalezca el respeto, equivale a la práctica real de los derechos humanos en su dimensión económica, social y política; no representa un ideal, es una posibilidad que debe buscar el hombre para mejorar su supervivencia.

\section{Educación para la paz}

Monclús y Saban (2008) definen educación para la paz como "la dimensión esencial de la cultura de paz" (p. 73), que tiene la finalidad de aportar fundamentos necesarios para formar mejores ciudadanos del mundo. Debe ser un proceso de participación y formación que incida en el desarrollo de la capacidad crítica, frente a las nuevas realidades y conflictos de estas sociedades, que conduzca a las personas a asumir posturas en favor colectivo. Debe ser un proceso transversal en contenidos que impacte en todos los niveles de la educación, que facilite la apertura a otras ideas y posturas para que el encuentro en el debate y la deliberación conduzcan a acuerdos y convenios para aprender a vivir juntos y se ocupe de la transformación de la cotidianidad.

Una educación para la paz debe ser una educación profunda, según Cely (2011) "que no le puede dar la espalda a la madre naturaleza e ignorarla, puesto que ella es nuestra casa terrenal, habitamos en ella y todos nosotros somos naturaleza, pues también ella nos habita cualquiera que sea su concepción" (p. 357). Evidentemente educar para la paz es una tarea de todos, en un país dolido por la guerra y los conflictos es una tarea humana que abarca la totalidad e integralidad de la vida de los seres; hoy más que nunca en la era de las comunicaciones la educación debe ser un diálogo compartido entre actores, donde se permita el desarrollo libre de la personalidad, se promueva la creatividad, la imaginación, se respeten los derechos y permita la reconstrucción de una sociedad que está enferma por la violencia.

Considerando que educar para la paz es una función amplia y compleja, en este trabajo solo se dará una breve mirada de la educación desde el punto de vista de la bioética y de la pedagogía de la liberación soporte d esta investigación, teniendo como concepción que los seres humanos son el punto único y central donde se reserva la valía, ética y moral de todos los seres vivos y el único que tiene a su alcance la posibilidad de construir y deconstruir la sociedad a su manera, para Jessica Bejarano, Eymer Chamorro y Diego Rodríguez (2018) "es tarea de la educación capacitar al ser humano en la formación crítica y argumentativa, capaz de sostener su propio disenso con firmeza, un ser humano capacitado para seguir los argumentos en lugar de seguir al rebaño es un ser valioso para la democracia" (p. 241).

La educación para la paz es resultado de una larga trayectoria, nace como consecuencia de la primera guerra mundial con el movimiento de Escuela Nueva con énfasis en educación para la comprensión internacional, pues dadas las circunstancias históricas era necesario trabajar con el propósito de superar las tensiones y discordias entre las naciones, después de la segunda guerra mundial se dio prioridad a la comprensión internacional mediante la cooperación entre las naciones y las relaciones interculturales, surge con mayor solidez con la creación de las Naciones Unidas, específicamente la Unesco con el objetivo de promover una educación a partir de los Derechos Humanos y el desarme. Para Herrero (2003) la iniciativa consistía en "impulsar y fomentar internacionalmente la paz en la educación" (2003, p. 288). Hacia la década de los años 60, la educación para la paz surge como disciplina científica, así a finales del año 1959 se crea en Oslo el Instituto de Investigación Social con ideas de Johan Galtung sobre 
la violencia. Ya en los años 70 la preocupación se centró en el control de las armas dada la carrera armamentista de los países desarrollados. Por los años 80 el interés de la educación para la paz se da en torno a la convivencia cercana entre las personas, en la escuela, en las instituciones, las comunidades; ya por los años 90 la educacion para la paz se fija en las relaciones interculturales entre regiones y personas, dada la emergencia e influencia de las tecnologías de la información. Hoy la educación para la paz está comprometida "con enseñar a vivir, convivir y habitar correctamente (...) en un solo planeta que es la casa de todos" (Cely, 2011, p. 353).

Para Freire (1999) "[...] la violencia es la constante" (p. 32), por tanto, educar para la paz es una prioridad que aspire transformar las violencias que se multiplican diariamente, en ese sentido, Amaral Gómez (2013) considera que "la educación para la paz, ante todo en América Latina, es un llamado a la reinvención de las formas educativas que contribuya a la transformación de las diferentes manifestaciones de violencia" (p. 17). Pienso que la clave es aprender a convivir.

No es una tarea fácil, tampoco es imposible, pero demanda acuerdos humanos, políticos y sociales para alcanzar los cambios que se pretenden en la convivencia. En ese orden de ideas, es necesario situar la educación para la paz,

en el marco de una educación pluridimensional mediante la cual la persona, en distintos ámbitos y distintos momentos a lo largo de la vida aprende y construye conocimientos y valores a través del desarrollo del juicio crítico y de la acción (Alegre de la Rosa, 2006, p. 57).

En consecuencia, hoy la sociedad tiene un enorme compromiso con las nuevas generaciones, se debe promover la formación de un ser humano holístico en un mundo diverso, con herramientas que fomenten la construcción de sociedad pacífica.

Educar para la paz y la convivencia es un objetivo defendido por todos los sectores de la comunidad educativa. No sólo el futuro, sino el presente depende de que nuestros niños, adolescentes y jóvenes aprendan a resolver sus conflictos por vías pacíicas. Por eso, es muy importante que los alumnos adquieran "herramientas" y procedimientos para este fin y que vayan asumiendo valores que se traduzcan en actitudes y hábitos de convivencia (Laguna, 1998, p. 5).

\subsection{Potter por una educación reflexiva para la transformación}

La propuesta del médico Potter nos hace pensar en la importancia de educar para la reflexión crítica y la responsabilidad de cada una de las acciones del ser humano en el mundo, tanto como en sus derechos y los de todos los seres vivos; hay que educar para humanizar a la humanidad y preparar a los individuos para la vida que es diversa y muy compleja, en ese sentido Wilches (2015) dice que "la educación no puede ser ajena a la problemática social y a la crisis del sistema" (p. 180). Desde esta perspectiva "la bioética es la clave para trabajar por un cambio de paradigma que transforme las bases de la cultura y la educación predominantes en el mundo global en el que vivimos" (Quintanas, 2009, p. 1).

En efecto, para la bioética, la educación debe ser humanista y como proceso debe estar orientada a formar valores morales de respeto, honestidad, generosidad solidaridad, sinceridad e incorporar experiencias individuales, vivencias familiares, y sociales, así como mecanismos de autorregulación que encaminen al cambio y se establezcan como rutas ideales para el actuar todos los días de una persona y de una sociedad.

Dadas las pretensiones de la bioética, la educación debe ir más allá de asignaturas aisladas y clases magistrales tradicionales que minimizan la creatividad y la libertad, demanda un ambiente de investigación que permita construir conocimiento, a través del encuentro permanente entre diferentes campos del saber, porque es una disciplina integradora, dialogante que fortalece y direcciona los aprendizajes desde hechos reales y dilemas propios de la humanidad; dicha 
posición dialógica hace posible la toma de decisiones frente a circunstancias propias de la vida del hombre y de los todos los seres vivos, lo cual hace del aprendizaje un proceso interactivo que responde a realidades ciertas, donde además se tienen en cuenta ambientes socioeconómicos y culturales, así como políticas públicas, fundamentales para soportar legalmente la transformación de la educación. Precisamente: "desde la bioética, se debe decidir cuáles son los ejes sobre los que pivota la educación que se desea promover, qué tipo de ciudadano y qué valores se deben trabajar". (Casado, 2011, p. 67).

\subsection{Freire por una educación liberadora para la transformación}

A consideración de Freire "antes que nada debemos saber qué clase de educación es la que la gente realmente quiere, porque muchas veces discutimos acerca del contenido de la educación para las personas sin tener en cuenta sus verdaderas necesidades" (Freire, 1986b, p. 44). En consecuencia, no existe una educación, existen las educaciones, lo cual se refiere las distintas formas en que los seres humanos asumen la realidad y parten de ella para construir nuevas experiencias, para alcanzar otros objetivos y en ese devenir constante transformar esos escenarios que oprimen y devastan la naturaleza humana.

En efecto, Freire propone una educación que se articule con las necesidades integrales de las personas, que permita pensar, que facilite la praxis, la transformación de sujeto, de contexto y de estructuras sociales, una educación de interacciones permanentes entre teoría y práctica. La verdadera educación da libertad, es poderosamente humana y arriesgada.

Freire habla de libertad, justicia e igualdad, cree en estas palabras en la medida en que ellas estén encarnando la realidad de quien las pronuncia. Sólo entonces las palabras, en vez de ser vehículo de ideologías alienantes, o enmascaramiento de una cultura decadente se convierten en generadoras, en instrumentos de una transformación auténtica, global, del hombre y de la sociedad. Por esto mismo es que para Freire, la educación es un acto de amor, de coraje; es una práctica de la libertad dirigida hacia la realidad, a la que no teme; más bien busca transformarla, por solidaridad, por espíritu fraternal (Olivera, y Orellana, 2005, p. 36).

Por tanto, una educación auténtica puede integrar al individuo con su realidad social, porque los seres humanos no están en el mundo, están con el mundo, esta es la esencia de su propuesta, y "no existe educación sin sociedad humana ni existe hombre fuera de ella" (Freire, 1977, p. 25).

La conexión entre Freire y Potter es amplia, los dos manifiestan que la educación es un proceso humano que implica interacción, que debe surgir de la reflexión y toma de conciencia frente al mundo real que viven las personas y las sociedades, debe integrar los objetivos de las ciencias, debe fundamentarse en los derechos humanos, y los valores supremos del hombre como la autonomía, justicia, y libertad, tanto como en la ética de la tierra, debe estar cimentada en el diálogo conciliador y legítimo que permita el debate y el consenso frente a su propio destino y a la conservación de la especie. Potter y Freire concuerdan en que el ser humano debe ser el centro de toda propuesta educativa

\section{Cultura de paz}

La evolución de la historia de la humanidad siempre ha estado permeada por violencia, conflictos y guerras, desde esa perspectiva Federico Mayor Zaragoza (2017) recuerda que "desde el origen de los tiempos los gobernantes han seguido el perverso adagio de 'si vis pacem, para bellum', es decir, si quieres la paz, prepara la guerra. El poder absoluto masculino ha ejercido siempre sus funciones basado en la imposición y el dominio" (2017, p. 41).

Infortunadamente, hoy en pleno siglo XXI, todo parece igual, se puede denunciar que la violencia es permanente, recurrente, inhumana cruel, despiadada y persistente, solo que se han 
transformado las formas de hacerla, hay nuevos elementos que aumentan vertiginosamente este estado violento, para Oñate (2015)

\begin{abstract}
El potencial de autodestrucción que la humanidad misma ha creado durante el siglo $\mathrm{XX}$ y que se ha visto exacerbado en el siglo XXI se acrecienta. La cultura de violencia en la que nos encontramos, y que afecta a la escuela, es contraria a la cultura de paz que la escuela tiene responsabilidad de promover (p. 21).
\end{abstract}

Ante la destrucción y desesperanza que sufre diariamente gran parte de la humanidad, muchas instituciones, organizaciones, fundaciones y universidades han venido trabajando a ese respecto con iniciativas pedagógicas y alternativas de formación, por lo menos para disminuir poco a poco el avance de esta violenta forma de vida; así mismo han sido agentes líderes en procesos de negociación para la paz, como el que hace poco se firmó en Colombia. Sin embargo, esto no ha sido suficiente; hacen falta propuestas, y estrategias que consoliden nuevas alternativas, para que la paz no sea un sueño. Ante esa urgente realidad, la Unesco asume el liderazgo para la construcción de la cultura de paz, como una necesidad prioritaria para las sociedades de todos los países en el mundo; por lo menos en nuestro país es inaplazable, obliga a crear procesos de intervención social en busca de solidaridad, cooperación, pluralismo, diversidad, consenso, voluntad de entendimiento y reconocimiento, en las relaciones interpersonales, sabiendo que la paz en todos los ámbitos sociales es un derecho y un deber de obligatorio cumplimiento.

Una cultura de paz que comience en el seno de la familia, continúe en la escuela como compromiso de la educación de calidad, innovadora y humana que promueva valores como la no discriminación, la igualdad y el respeto por la vida de todos los seres de la naturaleza, como lo proponen Potter, desde la bioética, y Freire, desde la pedagogia liberadora. Deben ser caminos para andar la paz, que gire en torno al reconocimiento y valía de los derechos humanos, además de cimiento para la democracia; por tanto, se requieren actividades de integración, sensibilización, encuentro, reflexión, que susciten el desarrollo de habilidades para la vida. RedUnipaz (2015) reconoce que la cultura de paz requiere irremediablemente de la educación para la paz,

porque constituye:

$$
\begin{aligned}
& \text { El escenario de transformación para una cul- } \\
& \text { tura, es lo cotidiano, las relaciones cercanas, } \\
& \text { es allí donde ella se transforma. Esto eviden- } \\
& \text { cia el poder que tenemos para potenciar las } \\
& \text { transformaciones, por lo que insiste en la } \\
& \text { necesidad de una educación para la paz con- } \\
& \text { textualizada, fruto de pedagogías y procesos } \\
& \text { vitales y experienciales (p. 32). }
\end{aligned}
$$

Fisas (1998), propone los siguientes ejes que inciden esencialmente para construir cultura de paz, de los cuales menciono algunos

- Recuperar valores perdidos para que los individuos sean más responsables.

- Desarrollar ética global para socializarnos en la humanidad.

- Mejorar, ampliar y universalizar los derechos humanos.

- Desacreditar y deslegitimar la guerra, la violencia y el uso de la fuerza.

- Satisfacer las necesidades básicas.

- Potenciar el desarrollo de las personas.

- Potenciar el diálogo y el entendimiento entre culturas.

- Mejorar la gobernabilidad democrática y mayor participación de los ciudadanos.

- Priorizar las inversiones en el campo educativo.

- Incentivar una educación crítica y reflexiva.

A mi juicio son valiosas pautas, propias para empezar a consolidar el anhelo de paz, las cuales se ajustan a realidades de nuestro contexto y orientan propuestas en ese sentido, porque ir en busca de la cultura de paz es el reto del siglo XXI, en todo el mundo. Si pensamos en nuestro país es una obligación, un compromiso 
ético de quienes tenemos en nuestras manos la formación de nuevas generaciones en una nueva sociedad que no se detiene por la velocidad de la globalización.

\subsection{Cultura de paz desde las aulas}

Cultura de paz es la búsqueda de una construcción armónica en el desarrollo de la vida personal y colectiva en un escenario de adhesión y tolerancia. La idea de cimentar paz no es nueva, la Unesco en 1989 promovió numerosas actividades en torno a esta esperanza de construir paz. Se han alcanzado grandes logros, no obstante, lo más importante es que se han ganado espacios de reflexión en el sistema de Naciones Unidas, organismo que proclamó el 2000 como el Año Internacional de la Cultura de Paz; En el Congreso de Yamusukry Sobre la Paz en la mente de los hombres en Costa de Marfil en 1989 se sentaron las bases para la cultura de paz.

En ese sentido, la Declaración y el Programa de Acción sobre Cultura de Paz de la Unesco (1999, Resolución A/53/243, Art. 9) identifican ámbitos de acción para los actores a nivel local, nacional e internacional, recomienda que, para comenzar a promover una cultura de paz a partir de las aulas, es imprescindible comenzar a partir de

- Revisiones periódicas de planes de estudio, currículos y proyectos.

- Propuestas con proyectos sociales e inclusivos.

- La proyección de la enseñanza y práctica en valores, actitudes que tenga como ejes la reflexión y análisis de la realidad individual y colectiva, el respeto, la libertad, tolerancia, afecto, igualdad, inclusión

- El fomento de la comunicación participativa y democrática que permita la expresión libre de sentimientos, expectativas, proyectos de vida
- La orientación en el conocimiento y uso adecuado de las nuevas tecnologías de la información.

- Proyectos que garanticen la igualdad entre mujeres y hombres a través de acciones pedagógicas.

Indudablemente la cultura de paz se debe apoyar en los procesos educativos; para Potter y Freire es claro que aprender el valor y respeto por la vida de todos los seres de la naturaleza proviene de la educación. En consecuencia, los autores consideran que el primer paso es la reflexión, tener actitud de respeto para escuchar al otro, valorar sus sentimientos, dar oído a sus experiencias, simultáneamente trabajar la resiliencia, el compromiso, fraternidad y la tolerancia; para que prevalezca la comprensión recíproca.

La cultura de paz liberadora debe articularse con los sistemas económico, político y social, como parte del andamiaje que direcciona a la sociedad, teniendo como eje la educación participativa, significativa, dialogante y permanente, lejos de culpas y señalamientos, que forme para la paz y la transformación de la sociedad, como esperanza de vida y justicia para todos.

En ese orden de ideas, "cultura de paz supone un esfuerzo generalizado para modificar mentalidades y actitudes que promuevan la paz, es hacer que los niños y adultos comprendan y respeten los valores universales como justicia, libertad, democracia, los derechos humanos, igualdad, (...)" (Cabello et al., 2016, p, 26).

\section{Aspectos significativos del encuentro entre Potter y Freire}

Siendo teóricos de disciplinas diferentes y de contextos sociales y geográficos distantes, su análisis frente a la realidad y sus propuestas tienen vigencia y no están lejos de nuestros escenarios actuales cotidianos, por lo que se establecen posibles 
Cultura de paz desde las aulas.

Un encuentro entre Potter y Freire

aproximaciones entre la bioética de Van Ressenlaer Potter y la pedagogía de la liberación que se ha identificado a partir de la propuesta de Paulo Freire, como resultado del estudio exhaustivo de sus obras, en este caso he considerado que los autores trabajaron por:

- Carácter dialógico en torno al valor del ser humano y de la vida y su contexto que puede ser transformado que Freire plantea como dialogo con la realidad y Potter pide como esencia de la ética de la vida.

- Reconocimiento a la diversidad a través del respeto por las diferencias, sentimientos, emociones y necesidades buscando el beneficio común.

- Unidad entre ciencia y valores, que Potter considera construcción del puente entre las ciencias, lo que podemos definir como la humanización del conocimiento.

- Transdisciplinariedad por cuanto el individuo es un sistema complejo que se desarrolla en realidades propias y diversas que se integran

- Autonomía como resultado del proceso de concientización, reflexión, el cual es posible a través de la educación crítica y problematizadora, que podemos definir como educación liberadora como lo propone Paulo Freire

- Potenciar el conocimiento, el desarrollo individual y colectivo desde el encuentro de saberes.

- Satisfacción de necesidades básicas como cimiento para la justicia que define Potter y equidad que reclama Freire.

- Interculturalidad como interacción entre diferentes culturas y formas de pensar

Los autores reclaman igualdad, justicia, responsabilidad, tolerancia, compromiso, transformación no solo al hacer ciencia sino al aplicarla, autonomía y derechos, pensar en la bioética como saber que direccione el quehacer pedagógico y la utilización de la ciencia en favor de la vida.

\subsection{Humanizar el conocimiento}

Potter y Freire creen que al humanizar el conocimiento este debe estar al servicio del ser humano como una forma de mantener y mejorar su condición humana, debe ser considerado sabiduría que construye vida, la protege y conserva. La humanización del conocimiento demanda ajustar contenidos, planes de estudio, currículos, aprendizajes y todas las acciones pedagógicas en torno a las necesidades particulares de las estudiantes ajustadas a las necesidades y requerimientos del contexto. El conocimiento como se lee en Freire y Potter debe estar comprometido con la vida, y los derechos humanos. La humanización del conocimiento es un enfoque que se dirige a orientar la formación del ser humano desde la responsabilidad individual, y social, la autonomía, la concertación, es el conocimiento que se necesita para la persona, la familia y la sociedad.

\subsection{Educación liberadora}

Demanda la resignificación de la educación, es una propuesta que se aleja del tradicionalismo y acumulación de saberes sin sentido, es la educación que se compromete con el desarrollo del hombre y de la sociedad, que parte del conocimiento responsable y crítico de la propia realidad con el objetivo de transformarla en beneficio de la vida la justicia y la equidad, es una educación dialogante, propositiva que en unión con la bioética proveen fundamentos para cimentar y formalizar la educación para la paz desde las aulas.

\subsection{Respeto y conservación de la especie humana por una supervivencia ideal}

En las lecturas se percibe que ambos trabajaron por el ser humano como persona, el medio ambiente como soporte para la vida, el respeto a la conservación de la especie humana como fundamento de la existencia, el reconocimiento de todos los ámbitos de la humanidad como contextos para el desarrollo libre de las personas, la protección a la vida en toda su esencia, la 
insistencia de una vida digna que se manifieste en una supervivencia ideal alejada de la opresión y el sufrimiento, el crecimiento de cada individuo a partir de una educación reflexiva, problematizadora, interdisciplinaria, fuente para el avance de la ciencia y la cultura dentro de los límites de la autonomía e igualdad.

\section{Conclusiones}

La revisión bibliográfica juiciosa y profunda de los autores definidos para este trabajo ha permitido comprender que a pesar de que ellos pertenecían a distintos horizontes políticos, sociales y económicos y con diferente formación académica tienen aspectos en común en sus propuestas, que se conjugan en torno al cuidado de la humanidad, la libertad y la justicia, que trabajan en procesos participativos, inclusivos, democráticos de toma de conciencia orientados por debates cuyo eje central son los principios éticos universales que se han mencionado. Es responsabilidad de la educación y por supuesto de la bioética, orientar la formación de las personas para construir una sociedad pacífica.

La educación para la paz debe comenzar desde los primeros años de vida en la familia, continuar en las aulas y trascender en las colectividades, de manera que todas las personas se empoderen desde muy temprana edad con autonomía y decisión y se comience a construir una convivencia diferente, donde se pueda vivir sin distinción alguna. Razón de más para pensar que hay que educar en la vida para la vida, porque no solo conocimientos y destrezas, ni solo ciencia y técnica enseñan a discernir el sentido de las cosas, porque "la persona necesita encontrar el sentido de lo que vive, la finalidad de lo que pasa en sí mismo y a su alrededor, necesita razones o argumentos para actuar en cualquier situación" (Zurbano, 1998, p. 12).

Por tanto, se requiere formación integral para la paz, con ambientes también de paz siguiendo los principios tomados de los planteamientos de Freire y Potter y una formación que
- Gire en torno al hombre y sociedad del siglo XXI.

- Genere el diálogo reflexivo comprensivo y conciliador.

- Promueva la investigación y el uso del conocimiento científico para solucionar problemas de la humanidad, de la convivencia y supervivencia.

- Sea inclusiva, pertinente y permanente

- Flexibilice y ajuste los planes de estudio en entornos de paz incluyendo la propuesta de la bioética y la pedagogía de la liberación como disciplinas emergentes, contemporáneas, transdisciplinares que involucran los derechos sublimes del hombre como la dignidad, libertad, justicia y respeto.

- Presente estrategias pedagógicas, académicas y de convivencia mediadas por nuevas tecnologías para que se involucren con las alternativas actuales de aprendizaje y formación

- Promocione nuevas metodologías que promuevan un aprendizaje dinámico y objetivo

- Consolide educación, ciencia y cultura e incluya tradiciones, costumbres y las aspiraciones y expectativas de las comunidades.

Definitivamente, para comenzar a consolidar cultura de paz desde las aulas no solo se necesitan sólidas bases teóricas, sino reformulación de planes de estudio, de trabajo, de currículos y buenas intenciones, así como de políticas públicas que viabilicen la puesta en marcha de proyectos sociales, comunitarios, pedagógicos que sean pertinentes e inclusivos, que construyan y transformen la violencia que estamos viviendo persistentemente en todos los ámbitos sociales. Necesitamos de la bioética porque es un "saber interdisciplinario y transdisciplinario en permanente construcción que pone de relieve los valores éticos y morales indispensables para aprender a vivir, convivir y habitar correctamente nuestra casa terrenal, la casa de todos" (Cely, 2011, p. 365). Necesitamos de la pedagogía liberadora que busca la igualdad entre las personas y la transformación de la academia. 
Cultura de paz desde las aulas.

Un encuentro entre Potter y Freire

\section{Referencias}

Aguilar, M. y Castañón, N. (2013). Una visión sobre la educación para la paz. Revista Humanidades y Ciencias de la Educación, (Almanaque \#3), 70-81.

Alegre de la Rosa, O. (2006). Cultura de paz, diversidad y género. Revista Investigación en la escuela, (59), 57-68.

Benavides, P. (2012). Van Ressenlaer Potter, pionero de la ética Global. Revista Rencuentro, (63), 8-22.

Bejarano, J., Chamorro, E. y Rodríguez, D. (2018) La escuela pensada desde el Pluralismo a favor de una cultura de paz. Revista Sophia, (24), 239-263.

Cabello, P., Carmona, S., Gorjon, F., Iglesias, E., Sáenz, K. y Vásquez, R. (2016). Cultura de paz. Ciudad de México, México: Editorial Patria.

Casado, M. (2011). Sobre la necesidad de adoptar una concepción de la Bioética flexible y que promueva la educación en los principios de la Declaración Universal de los Derechos Humanos. Revista Latinoamericana de Bioética, 11(2), 62-70.

De la Cuesta, A. (coord.). (2005). Bioética y derechos humanos. Implicaciones Sociales y jurídicas. Sevilla, España: Universidad de Sevilla.

Cely, G. (2011). Educación Bioética para vivir, convivir y habitar. Un plus a la Capacitación profesionalizante. Cuadernos de Contabilidad, 12(30), 353-367.

Clastres, P. (2004). Arqueología de la violencia: la guerra en las sociedades Primitivas. Ciudad de México, México: FCE.

Echeverría, R. (1997). El Búho de Minerva. Introducción a la Filosofía Moderna. Santiago, Chile: Editorial Dolmen.

Fisas, V. (1998). Capítulo XI del Libro Cultura de paz y gestión de conflictos. Barcelona, España: Icaria/ UNESCO.

Freire, P. (1969). La Educación como práctica para la libertad. Montevideo, Uruguay: Editorial Siglo XXI.

Freire, P. (1977). La educación como práctica de la libertad. Madrid, España: Siglo XXI Editores.

Freire, P. (1986a). Hacia una pedagogía de la pregunta. Buenos Aires, Argentina: Ediciones Aurora.

Freire P. (1986b). La Educación: autocrítica de Paulo Freire / Iván Ilich. Buenos Aires, Argentina: Ediciones Búsqueda.

Freire, P (1999). Pedagogía de la autonomía. Iztapalapa, México: Siglo XXI Editores.

Freire, P. (2002). Educación y cambio. Buenos Aires, Argentina: Editorial Galerna.

Galtung, J. (1996). Cultura de paz y gestión de conflictos. Londres, Reino Unido: Sage Publicaciones.

García, J. (2014). Concepción antropológica de Paulo Freire en la obra pedagogía del oprimido. Revista de Investigación Silogismo, 1(13), 22-32. Recuperado de http://www.cide.edu.co/ojs/index.php/ silogismo 
Gómez, A. (2013). Teoría de la educación para la paz en América Latina. Revista de Ciencias de la Educación Academicus, 1(3), 6-19.

Harris, M. (1999). El desarrollo de la teoría antropológica. Una historia de las Teorías de la Cultura. Madrid, España: Siglo XXI.

Herrero, S. (2003). Reseña de educación para la paz su teoría y práctica de Xesús R. Jares. Convergencia Revista de ciencias sociales, 10(33), 285-298.

Hurtado, I. y Toro, J. (2007). Paradigmas y métodos de investigación en tiempos de cambio. Caracas, Venezuela: Editorial CEC.

Jiménez, F. (2011). Racionalidad pacífica. Una introducción de los Estudios Para la paz. Capítulo VI. Madrid, España: Editorial Dykinson.

Jiménez, F. y López, M. (2007). Hablemos de paz. Pamplona, Colombia: Editorial Universidad de Pamplona.

Kung, H. (1977). Ser cristiano. Barcelona, España: Editores Cristiandad.

Laguna, J. M. (1998). Presentación. En J. L. Zurbano, Educación para la convivencia y para la paz (pp. 5-6).

McLaren, P. (2006). La enseñanza contra el capitalismo global y el nuevo Imperialismo: una Pedagogía crítica. California, US: Editorial Popular.

Mayor, Z. (2017). Cultura de paz y no violencia. Transición histórica de la fuerza a la palabra. Revista: Cuenta y Razón, (40), 41-43.

Monclús, A. y Saban, C. (2008). Educación para la paz Actualidad y propuestas. Barcelona, España: CEAC Editores.

Ocampo, R. (2010). La paz como construcción ético-política de base. Revista Nova et Vetera, 19(63), 49-59.

Olivera, E. y Orellana, Á. (2005). Escuchemos a Paulo Freire: una mirada a la Educación Popular. Revista Electrónica Diálogos Educativos, 5(10). Recuperado de http://www.umce. cl/ dialogos/

Oñate, O. (2015). Cultura de paz para la escuela en tiempos de violencia (tesis de doctorado). Universidad de Carabobo, Valencia, Venezuela.

Pineda, R. (2008). La concepción de ser humano en Pablo Freire. Revista Electrónica Educare, XII(1). Recuperado de http://www.revistas.una.ac.cr/indexo

Perdomo, C. (2009). Dimensión antropológica del pensamiento Antropológico de Paulo Freire. Tegucigalpa, Honduras: Biblioteca virtual de Honduras.

Potter, V. (1970). Bioethics Bridge to the future. New Jersey, US: Prentice-Hall.

Potter. V. (1971). Bioethics: The science of survival. Perspectives in Biology and Medicine, 14(1), 127-153.

Potter, V. (1988). Global Bioethics. East Lansing, US: Michigan State University Press. 
Quicutis, L. (2013). Potter y Freire: diálogo de fundamentos teóricos para la educación bioética. Revista Bioética, 21(1), 158-167.

Quintanas, A. (2009). Una ética para la vida en la sociedad tecnocientífica. Sinéctica, 32(1). Recuperado de http://www.scielo.org.mx

RedUnipaz (2015). Pensar en educación para la paz. Apuestas del Encuentro Nacional de Educación para la paz. Recuperado de http://redunipaz.org/web/files

Rojas, I. (2011). Hermenéutica para las técnicas cualitativas de investigación en Ciencias sociales: una propuesta. Revista Espacios Públicos, 14(31), 176-189.

Streck, D., Redín, E. Y Zitkoski, J. J. (Orgs.) (2015). Diccionario de Paulo Freire. Lima, Perú: Editora Auténtica CEAAL.

UNESCO. (1999). Programa de Acción sobre una Cultura de Paz. Asamblea General. 107a. Sesión plenaria. A/RES/53/243. Artículo 9. Página 5. Recuperado de www.UNESCO.org/ iycp/kits/sp_res243.pdf

Wilches, A. (2015). Cruce de caminos entre Bioetica y Educación ambiental. Revista RedBioetica/ UNESCO, 6,1(11), 176-186.

Wilches, Á. (2011). La propuesta Bioética de Van Ressenlaer Potter. Cuatro Décadas después. Revista Opción, 27(66), 70-84. 